\title{
Business Administration Students As Surrogates For IT Professionals Summary Of A Study
}

Melinda Cline, Georgia Gwinnett College, USA Jeremy St. John, Texas A\&M University-Commerce, USA

Carl S. Guynes, University of North Texas, USA

\begin{abstract}
The purpose of this paper is to report a summary of the results of a study which examined the appropriateness of using business school students as surrogates for IT professionals by comparing cognitive styles, physiological characteristics, and basic demographic data among the two groups. Cognitive style refers to the way individuals think, perceive and remember information. MyersBriggs Type Indicator (MBTI), Kolb's Learning Style Inventory (LSI), and Human Information Processing Survey (HIPS) tests were used to examine cognitive style. Physiological characteristics examined include dichotic (different ear) listening and visual perception speed, both with laterality (right/leftness). This study identifies important differences between the students and IT professionals. The results have implications for both researchers and designers of future information systems.
\end{abstract}

Keywords: Cognitive Style Human Factors; Human Information Processing; Individual Differences; Learning Style

\section{INTRODUCTION}

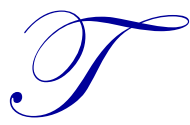

his study examined the appropriateness of using business school students as surrogates for IT professionals using three cognitive style measurement instruments, two physiological tests with laterality, and basic demographic data. Cognitive style refers to the way individuals think, perceive and remember information. The research methodology is a repeated measures experimental design performed using 77 participants. The participants included 40 undergraduate/ graduate business majors and 37 information technology professionals. The instruments used include:

\section{Cognitive Style Instruments}

- $\quad$ Myers-Briggs Type Indicator (MBTI)

- $\quad$ Kolb's Learning Style Inventory (LSI)

- Human Information Processing Survey (HIPS)

\section{Physiological Characteristics}

- $\quad$ Dichotic listening task

- Tachistoscopic task

\section{PRIOR RESEARCH}

Information systems researchers recognize the importance of individual learning styles. Mehigan and Pitt reported two different studies of learning style, one in 2010 and the other in 2012. Bachari, Abdelwahed, and Adnani (2012) and Gunduz and Ozcan (2010) examined the importance of learning style in training. Alaka (2011) 
highlights the importance of learning style in the areas of career counseling, personnel selection, and coaching and training of information systems users. Felder and Brent (2005) state that one of the key goals for information systems is to provide the decision maker with a set of capabilities to apply in a sequence and form that fits his or her cognitive style.

Kinley (2013) indicates researchers in cognitive styles have applied memory, thinking, and problem solving as traits reflective of cognitive styles. Kraemer,Rosenberg and Thompson (2009) presents classifications of cognitive style including simple/complex, leveling and sharpening, focusing versus scanning, and field dependence versus field independence. Other researchers (Massa, and Myers. (2006), Kinley, Tjondronegoro, Partridge and Edwards (2014) ) have also conducted cognitive style studies to analyze individual performance.

This study expands on prior work (Jung 1938), (Mason and Mitroff 1973), (Myers and McCaully 1985), and (Sein and Robey 1993) by examining learning style as a construct to compare business students with information systems professionals to determine if business students are sufficiently similar to information systems professionals and appropriate, therefore, to be used as surrogates.

\section{RESEARCH METHODOLOGY}

The experimental design was a repeated measures design, also referred to as a within-subjects design. This design involves exposing the same subject to multiple treatments; in this case, psychological and physiological tests. The experimental design repeatedly treats each subject. The variations caused by different treatments are reflected by differences within the same person's performance, rather than between different groups. Each subject in this study completed several pencil and paper tests including the MBTI, LSI, and HIPS in a randomly assigned manner.

Moderating variable data was collected using separate questionnaires; one designed for student data collection and the other for IT professional data collection. The demographic data collected from the students included age, sex, college major, number of college hours completed, year in college, undergraduate degree for those students that were in graduate school, current or final college GPA, and ethnicity. In addition, data collection included measurements about the subject's physiological characteristics. These included diagnosis of dyslexia, the wearing of corrective lenses, and if the subject was hard of hearing. These were of importance as they have to potential to impact the subject's performance on the dichotic listening task and the tachistoscopic task. The questionnaire provided to the professionals was very similar with minor exceptions. The professionals were also asked to provide their job title, along with the number of years of work experience since college graduation.

\section{STATISTICAL HYPOTHESES}

A correlation matrix was generated which compared results from the dichotic listening task, tachistoscopic task, and the laterality index with cognitive style as measured by the MBTI, HIPS, and LSI. In addition, the tests included discriminant analysis using left-brain, integrated-brain, and right-brain dominant subsets as the three groups. The classifications of the three groups were on the derived laterality index, the dichotic listening index, the tachistoscope index, and the handedness index. The null hypotheses were:

H1: No statistical relationship exists between cognitive style as measured by the LSI and cerebral dominance.

H2: No statistical relationship exists between cognitive style as measured by the MBTI and cerebral dominance.

H3: No statistical relationship exists between cognitive style as measured by the HIPS and cerebral dominance.

A major goal of this research effort was to compare results of the cognitive style instruments as they are commonly used in IT research. Hypothesis 4,5 and 6 consider the relationships among the cognitive style instruments. The null hypotheses are: 
H4: No statistical relationship exists between cognitive style instruments MBTI and LSI.

H5: No statistical relationship exists between cognitive style instruments MBTI and HIPS.

H6: $\quad$ No statistical relationship exist between cognitive style instruments LSI and HIPS.

A correlation matrix comparing the cognitive style measures was used to test hypotheses 4,5 and 6 . This provided an indication of whether a relationship existed between the subscales of the instruments in what they measure.

\section{RESULTS OF THE STUDY}

The following section discusses the findings of the previously stated hypotheses with a summary presented in Table 1. Testing of hypotheses 1,2 and 3 was accomplished by two methods. A correlation matrix compared results from the cerebral dominance measurements with the multiple cognitive style measurements and a threegroup discriminant analysis was performed using left-brain, integrated-brain, and right-brain dominant subsets. The basis for the three groups was on the derived laterality index, the dichotic listening index, the tachistoscope index, and the handedness index.

\section{Hypothesis 1}

Hypothesis 1 stated that no statistical relationship existed between cognitive style (as measured by the LSI) and cerebral dominance. When looking at the same correlation for each group, none of the correlations were significant at the .01 level. Only the IT professionals had a high classification rate using the LSI as the discriminator. Of the IT professionals, $86.49 \%$ correctly classified into the proper laterality categories using LSI as the discriminator. The majority of the other correct classification percentages were 50\% or below. From these two statistical tests, it is apparent that a statistical relationship does not exist between the LSI and cerebral dominance.

\section{Hypothesis 2}

Hypothesis 2 stated that no statistical relationship existed between cognitive style (as measured by the MBTI scales) and cerebral dominance. There were no correlations that were significant at an alpha of .01. Discriminant analysis was slightly better than the LSI discriminant analysis, although still not at an acceptable level. The highest correct classification percentage of $78.38 \%$ was again using the Laterality index on IT professionals. The dichotic index may be fairly strong with correct classification percentages ranging from $57.50 \%$ for the business majors up to $62.16 \%$ for the IT Professionals. From these tests, a statistical relationship does not exist between the MBTI scales and cerebral dominance.

\section{Hypothesis 3}

Hypothesis 3 stated that no statistical relationship existed between cognitive style (as measured by the HIPS) and cerebral dominance. This hypothesis is a very important one since one would expect direct correlations between a pencil and paper test that purportedly measures cerebral dominance and physiological tests that purportedly measure cerebral dominance. There was only one correlation that was significant at the .01 level. For IT professionals, handedness had a -.49 correlation with left-hemisphere dominance which was significant at a $\mathrm{p}=$ .001. This significant correlation is not important based on the history of handedness being a confounding factor in cerebral dominance studies.

HIPS as a discriminator for cerebral dominance was not very strong. The highest correct classification percentage was $75.68 \%$ for IT professionals using the handedness index. This was not unexpected since the highest correlation found was with the handedness index in the IT professionals group. The business major percentage was $60.53 \%$. Thus, no statistical relationship exists between the HIPS instrument and the physiological measurements of cerebral dominance. 


\section{Hypothesis 4}

Hypothesis 4 stated that no statistical relationship existed between the cognitive style instruments (as measured by the scales of the MBTI and LSI). The LSI scale of CE (concrete experience) correlated with several of the MBTI scales. When examining the IT professionals subset, a correlation of -.24 existed. In addition, the correlation of .38 between the MBTI and LSI as significant in the current study at .023 . Based on the instability of these correlations, the conclusion is that consistent relationships do not exist between the MBTI and LSI scales.

\section{Hypothesis 5}

Hypothesis 5 stated that no statistical relationship existed between the cognitive style instruments (as measured by the MBTI and HIPS). Several correlations existed between the HIPS left and right scales with the MBTI scales. Positive correlations were indicated with the right scale. Negative correlations existed with the left scale. These correlations were significant at the .05 vel. The direction of these relationships are consistent with the beliefs that intuitives are more right brain dominant in their actions.

\section{Hypothesis 6}

Hypothesis 6 stated that no statistical relationship existed between cognitive style instruments (as measured by the scales of the LSI and the scales of the HIPS). This hypothesis encountered the same stability problem with the LSI as experienced in previous hypothesis tests involving the LSI. Although significant correlations existed with the HIPS left and integrated scale for several of the entries, the correlations did not remain significant for all groups. Consequently, this hypothesis is not rejected. A significant relationship did not exist between any of the LSI scales and the HIPS scales. The LSI was established to have very unstable correlations with other cognitive style instruments.

Table 1: Hypotheses Results

\begin{tabular}{|l|l|c|}
\hline Hypothesis & \multicolumn{1}{|c|}{ Specific Hypothesis } & Supported/ Not Supported \\
\hline $\mathrm{HR}_{1 \mathrm{R}}$ & $\begin{array}{l}\text { No statistical relationship exist between cognitive style as measured by the } \\
\text { LSI and cerebral dominance. }\end{array}$ & Supported \\
\hline $\mathrm{HR}_{2 \mathrm{R}}$ & $\begin{array}{l}\text { No statistical relationship exist between cognitive style as measured by the } \\
\text { MBTI and cerebral dominance. }\end{array}$ & Supported \\
\hline $\mathrm{HR}_{3 \mathrm{R}}$ & $\begin{array}{l}\text { No statistical relationship exist between cognitive style as measured by the } \\
\text { HIPS and cerebral dominance. }\end{array}$ & Supported \\
\hline $\mathrm{HR}_{4 \mathrm{R}}$ & $\begin{array}{l}\text { No statistical relationship exist between cognitive style instruments MBTI } \\
\text { and LSI. }\end{array}$ & Supported \\
\hline $\mathrm{HR}_{5 \mathrm{R}}$ & $\begin{array}{l}\text { No statistical relationship exist between cognitive style instruments MBTI } \\
\text { and HIPS. }\end{array}$ & Not Supported \\
\hline $\mathrm{HR}_{6 \mathrm{R}}$ & $\begin{array}{l}\text { No statistical relationship exist between cognitive style instruments LSI and } \\
\text { HIPS }\end{array}$ & \multicolumn{1}{|c|}{ Supported } \\
\hline
\end{tabular}

\section{IMPLICATIONS and CONCLUTIONS}

The objective of this research was to identify in IT research both the instruments which do measure what they are purported to measure and to identify those instruments which have limitations regarding their results. Strengths and weaknesses of the instruments and methodologies were also identified. Comparison of several cognitive style measurement instruments commonly used in information systems research was a major purpose of this study. The determination of the limitations of existing instruments in IT cognitive style research was another goal. This study correlated the results from the pencil and paper instruments with physiological measurements. The purpose of the correlation was to provide evidence of the representativeness of pencil and paper cognitive style surrogate measurements and their correlation to left brain-right brain dominance

The research resulted in a measure of the intercorrelations along with the strengths and weaknesses of the most widely used cognitive style instruments in IT research. In addition, relationships were tested between the subjects' results on the cognitive style instruments and results from the laterality methodologies. 
The measurement of laterality in this study was operationalized by two physiological measurements. Those measurements were a dichotic listening task and a tachistoscope visual task. Also included was the Edinburgh Handedness Inventory as a measurement of handedness. Neither the dichotic listening task nor the tachistoscope visual task displayed any consistent relationships with the cognitive style and personality instruments. Several possible reasons existed for this lack of significant relationships. These tasks may be measuring another attribute besides laterality. For example, both tasks require considerable concentration on the part of the subject in completing the tasks. Also, subjects used various strategies in completing this task which may influence the results of these methods.

The majority of the results for the Information Technology professional group were significantly different from the IT majors group. This is an important finding in that it provides support to the hypothesis that students are not proper surrogates for professionals, at least in the information systems field.

The results from this study have implications for future behavioral research in IS. Researchers have gained additional knowledge about the applicability of various instruments in cognitive style research in IS. Research from this study encourages researchers to use comparable measures that are valid within the objectives of cognitive style research. This research leads to an improvement of the fundamental measurement of cognitive style, from an was perspective. In turn, this leads to a stronger cognitive style model. Researchers should take a more critical approach in the selection of cognitive style and personality measurement instruments in the future due to results from this study.

The results of the research provide information to designers of future information systems. By considering the business administration majors along with IT professionals, an improved understanding of individual differences could result. More productive information systems could be implemented through this improved understanding.

\section{AUTHOR INFORMATION}

Dr. Melinda Cline is a Professor of Management Information Systems in the School of Business at Georgia Gwinnett College in Lawrenceville, Georgia. She received her Ph.D. in Management and Information Science from Florida State University. Her research interests include information systems evaluation, information security, and project management. Her research is published in numerous journals including the Journal of Computer Information Systems, Information Systems Management, Decision Support Systems, and the Managerial Auditing Journal.

Dr. Jeremy St. John is an Assistant Professor of Management Information Systems at Texas A\&M University Commerce. He received his Ph.D. from the University of North Texas. His research interests include information technology offshoring, process virtualization, and supply chain management.

Dr. Carl Stephen Guynes is a Regents Professor of Information Technology at the University of North Texas. He received a doctorate in quantitative analysis from Texas Tech University. Dr. Guynes' areas of specialization are client/server computing, end-user computing, data administration, and information resource management. Some of the journals in which Dr. Guynes has published include and Communications of the ACM, Information \& Management, Information Systems Management, and the Journal of Accountancy.

\section{REFERENCES}

1. Alaka, A., M. Learning styles; what difference do the differences make? Charleston LA Review (September 2011).

2. Bachari, E., Abdelwahed, E., H., and Adnani, M., E. Design of an adaptive e-learning model based on learner's personality. Ubiquitous Computing and Communication Journal 5, 3 (2012).

3. Felder, R., and Brent, R. Understanding student differences. Engineering Education 94, 1 (2005).

4. Gunduz, A., and Ozcan, D. Learning styles of students from different cultures and studying in near East University. Procedia Social and Behavioral Sciences (2010). 
5. Jung, C. G., Psychological Types. New York: Harcourt, Brace, and Company, 1938.

6. Kraemer, D. J. M., Rosenberg, L. M., and Thompson-Schill, S. L. (2009). The neural correlates of visual and verbal cognitive styles. J. Neurosci 29, 3792-3798.

7. Kinley, Khamsum, Tjondronegoro, Dian W., Partridge, Helen L., \& Edwards, Sylvia L. (2014) Modeling users' web search behavior and their cognitive styles. Journal of the American Society for Information Science and Technology.

8. Kinley, K. (2013). Towards Modelling Web Search Behaviour: Integrating Users' Cognitive Styles Unpublished PhD thesis, Queensland University of Technology, Brisbane Australia.

9. Mason, R. O. and I. I. Mitroff, "A Program for Research on Management Information Systems," Management Science, (January 1973), 475-487.

10. Massa, L., and Mayer, R., E. Should multimedia instruction accommodate verbalizer-visualizer cognitive style? Learning and Individual Differences (2006), 321-336.

11. Mehigan, T., and Pitt, I. Individual learner style inference for the development of adaptive mobile learner systems. In Chapter 11, Mobile Learning Pilot Projects and Initiatives (Santa Rosa, California, 2010), R. Guy, Ed., Informing Science Press, pp. 167-183.

12. Mehigan, T., and Pitt, I. Detecting learning-style through biometric technology for mobile gbl. International Journal of Game Based Learning 2, 2 (April 2012), 55-74.

13. Myers, I. B. and M. H. McCaulley, Manual: A Guide to the Development and Use of the Myers-Briggs Type Indicator, Palo Alto, CA: Consulting Psychologists Press, 1985.

14. Sein, Maung K., and Daniel Robey, Learning Style and the Efficacy of Computer Training Methods," Perceptual and Motor Skills, 72 (1993), 243-248. 